\title{
EFFECTS OF HYDROLOGIC FLUCTUATIONS ON THE TRANSPORT OF FINE PARTICULATE ORGANIC MATTER IN THE NANAKITA RIVER
}

\author{
Sitang PILAILAR ${ }^{1}$, Takashi SAKAMAKI ${ }^{2}$, Yuko HARA ${ }^{3}$, Norihiro IZUMI ${ }^{4}$, \\ Hitoshi TANAKA ${ }^{5}$, and Osamu NISHIMURA ${ }^{5}$

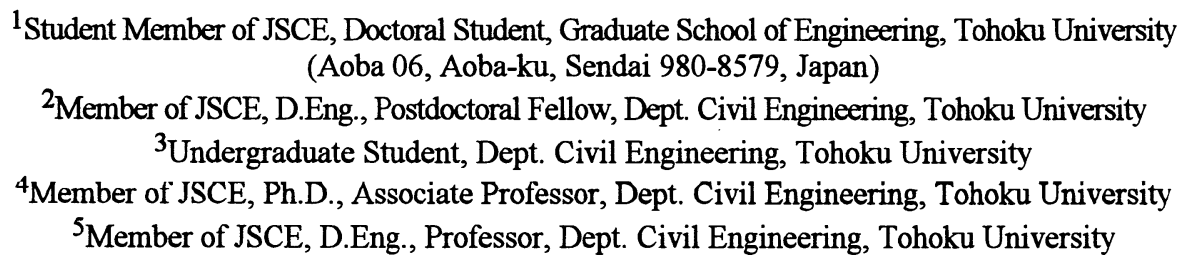

Field observations were conducted to investigate the transport process of fine particulate organic matter (FPOM) during a small flood in a lower reach of the Nanakita River. Sediment samples on riverbeds were collected at four stations before and after the flood. The flowing water was collected at three stations during the flood. The concentrations of suspended solid (SS) and particulate organic carbon (POC) were measured in both sediment and water samples. The total deposition and erosion rates of SS and POC were estimated from SS and POC in sediment samples. The time variation of the SS and POC concentrations, and the total transport rates were calculated from SS and POC concentrations in flowing water during the flood. The basic characteristics of the transport processes of SS and POC during a small flood in the Nanakita River were elucidated.

Key Words: sediment, fine particulate organic matter (FPOM), transport, entrainment, deposition

\section{INTRODUCTION}

Particulate organic matter (POM) in streams and rivers is an important energy source for microbes and invertebrates. It is also important for controlling the dynamics of contaminants because of its affinity for hydrophobic organic compounds ${ }^{1)}$. POM input of the small, headwater stream in the forest area are almost coarse particulate organic matter (CPOM:> $1 \mathrm{~mm}$ ), such as leaf litter from the terrestrial ecosystem ${ }^{2)}$. Once it has entered streams, it undergoes biological, chemical and mechanical degradation $^{3)}$. As processing proceeds, the degradation of CPOM causes increases in fine particulate organic matter (FPOM: $1 \mathrm{~mm}$ to 0.45 $\mu \mathrm{m})$ and dissolved organic matter (DOM: $<0.45$ $\mu \mathrm{m})$ in the downstream direction. While CPOM tends to be retained and accumulated within streams, FPOM and DOM are much easily transported because of their size. Thus, these fractions dominate in the export of organic matter in streams.

The concentrations and fluxes of particulate organic carbon, POC, and dissolved organic carbon, DOC, which represent the existence of organic matter, have been widely studied ${ }^{4)}$. In contrast, the exchange of FPOM between the sediment and the water column due to flow variation has not been evaluated despite a wealth of measurements of FPOM transported and stored in stream sediment ${ }^{5)}$.

The authors evaluated the resuspension and deposition rates, including biological productivity of FPOM during a low flow period ${ }^{6}$. In this study, the temporal and spatial variation of the FPOM concentration in the flowing water during a small flood caused by a small flood due to a typhoon is studied. The entrainment and deposition fluxes of FPOM due to hydrologic fluctuations have been assessed based on the amount of FPOM in the bed sediment before and after the flood and the amount of FPOM transported along the river during this period. 


\section{STUDY AREA}

The Nanakita River is about $45 \mathrm{~km}$ long with a drainage area of $200 \mathrm{~km}^{2}$. This study focuses on the lower reach of the river, 4 to $17 \mathrm{~km}$ upstream of the river mouth as shown in Figure 1. The riverbed gradient is about 0.0016 in the relatively upstream reach and about 0.0003 in the lower reach.

The predominant substratum of the upstream reach of Usugasawa weir is gravel, the median size, D50, of which is bigger than $2.7 \mathrm{~cm}$. In the lower reach, the riverbed consists of the mixture of sand and silt. The median sizes were found $0.055 \mathrm{~cm}$, $0.05 \mathrm{~cm}$ and $0.028 \mathrm{~cm}$ for Stations 2, 3 and 4, respectively. The previous study indicated that the sediment diameters decrease in the downstream direction along the river ${ }^{6}$.

\section{METHODOLOGY}

\subsection{Experiments and analysis of sediment and resuspendable FPOM}

In order to obtain the information on the spatial and temporal variations of the amount of resuspendable solid, bed sediment were collected at four stations, as depicted in Figure 1, on 7 Aug. and 11 Aug., before and after the flood on 9 Aug., 2003.

At Station 1 where the predominant bed material is gravel, the gravels were picked up by hand, and small gravel and sand were collected by core samplers with an inner diameter of $7 \mathrm{~cm}$. FPOM attached on the gravel was brushed and washed away with tap water, and kept in bottles. Three core samples were collected at each station, and gathered to get one sample. About $300 \mathrm{~g}$ of well mixed sample was then put into a $1,000 \mathrm{ml}$ bottle, filled with $900 \mathrm{ml}$ of tap water. The bottle was then shaken for 30 seconds. Slurry that consists of water and resuspendable fine solids was taken immediately.

At Stations 2, 3 and 4 where the riverbed consists of sand-silt mixture, bed sediment was directly collected by core samplers. The surface layers from 0 to $1 \mathrm{~cm}$ of 3 core samples were sliced and combined together, and was put into a $1,000 \mathrm{ml}$ bottle filled with tap water, in which the ratio between sediment and water is 1:3 by weight. The bottle was then shaken in the same way as done with samples at Station 1. Slurries were stored in a refrigerator under $5{ }^{\circ} \mathrm{C}$ until analyzed (always within 24 hours after collection) to minimize both microbial and physical effects on the quantity and quality of particles.

Slurries were filtered by $47 \mathrm{~mm}$ Whatman Glass Microfibre GF/C. The particles filtrated on the filter

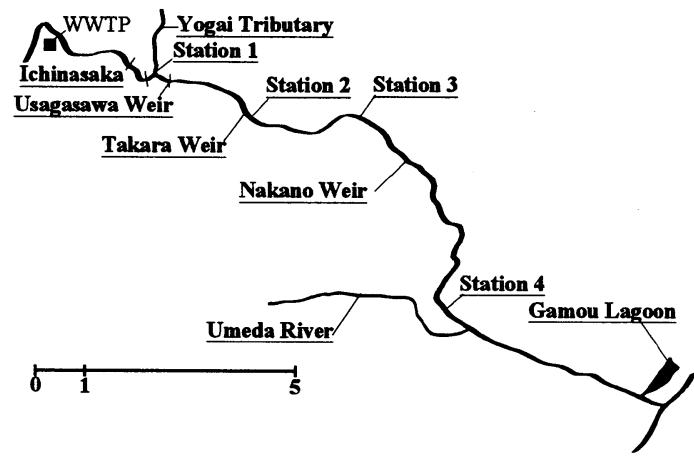

Fig.1 The Nanakita River, 17-km reach from river mouth: Sediment samples were collected from Stations $1,2,3$ and 4, flowing water samples were collected from Stations 1, 3 and 4.

paper were dried at $105^{\circ} \mathrm{C}$ and then weighed to determine the amount of suspended solids (SS) which represents the availability of resuspendable solids. The filtrated particle was analyzed by Technicon Auto Analyzer II to determine the particulate nitrogen (PN) and the particulate phosphorus (PP). The organic carbon included in resuspendable solids, which are called particulate organic carbon (POC) in this study, was determined by Shimazu TOC-5000A Total Organic Carbon Analyzer. In addition, the organic component was measured by ignition loss.

\subsection{Experiments and analysis of suspended solid in flowing water during periods of rapidly changing discharge}

The flowing water samples were collected during the flood period by portable auto samplers $S-4800$ at three stations; Stations 1, 3 and 4 (Figure 1). Water of $450-\mathrm{ml}$ was taken every 30 minutes. Two samples were gathered to get an hourly composite sample. The samples were analyzed to determine SS, PN, PP and POC by the same methods mentioned in 3.1. Additionally, particle size distributions of suspended particles in water samples were analyzed by Microtrac HRA x 100 Automated Small Volume Recirculator.

\section{RESULTS AND DISCUSSION}

\subsection{Rainfall intensity during sampling period}

The rainfall data at Izumigatake, which is the origin of the Nanakita River, recorded by Ministry of Land, Infrastructure and Transport, is presented in Figure 2. Typhoon No.10 brought a total rainfall of $23 \mathrm{~mm}$ and $8 \mathrm{~mm}$ on 9 Aug. and 10 Aug., respectively. 


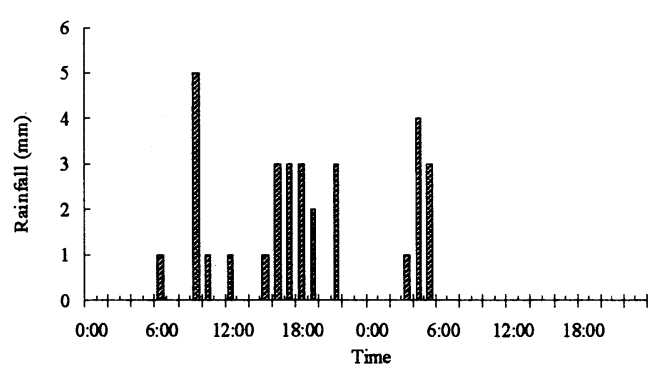

Fig.2 Rainfall due to Typhoon No. 10 during 9 Aug. to 10 Aug., 2003

\subsection{Spatial variations of FPOM before and after the flood}

The previous experiments and analysis of sediment ${ }^{7}$ suggested that the bed material available for resuspension ranges from 0.8 to $400 \mu \mathrm{m}$ in size, and that there is only a limited amount in the riverbed. The amount of resuspendable fine particles on 7 Aug before the flood at four stations is shown in Table 1. Fine particles at Station 1 were divided into 2 portions: particles attached on the gravel surface and existed in the gravel-sand mixture. The amounts were 4.4 and $11.2 \mathrm{mg} / \mathrm{cm}^{2}$ on gravel and in the gravel-sand mixed bed, respectively. The availability of fine particle in mixed bed at Station 1 was noticeably higher than Stations 2 and $3\left(5.2\right.$ and $7.0 \mathrm{mg} / \mathrm{cm}^{2}$, respectively). Meanwhile the amount of resuspendable solids on the bed shows an extremely high value of 52.2 $\mathrm{mg} / \mathrm{cm}^{2}$ at Station 4. Similarly, an abundant of POC was found at Station 4. Similar tendency was also observed during a low flow period from October to December ${ }^{6}$.

Table 1 also presents the information about fine particles left in the sediment after the flood. The remarkable decrease in SS and POC were found at Station 3 for $59 \%$ and $69 \%$, respectively. Decreases in SS and POC at Stations 1, 2 and 3 have been similarly observed in the previous observation after the flood in July $2002^{7}$. It was considered that most of FPOM was entrained and transported further downstream because of large bed shear stress and discharge during floods.

From the differences in the amount of SS between before and after the flood around four stations, the total entrainment and deposition for four days from 7 to 11 Aug. can be estimated.

At Station 1, the amount of SS attached on the gravel surface was removed by flow, and never increase for a short period because SS attached on gravels dominantly produced by biological activities. So we assume that the time variation of SS is represented by SS in the gravel-sand mixture. The total deposition rate at Station 1 is then estimated to be $25 \mathrm{~g} / \mathrm{m}^{2}$. At Stations 2 and 3, the total entrainment rate of fine solids was approximately $1.2 \mathrm{~g} / \mathrm{m}^{2}$ and $41.8 \mathrm{~g} / \mathrm{m}^{2}$, respectively. At Station 4, there was the accumulation of fine particles, the total deposition rate of which is 66.4 $\mathrm{g} / \mathrm{m}^{2}$.

The total entrainment and deposition of FPOM were also estimated based on POC data. It was found in this study that the ratio between POC and the total organic matter by weight ranges from 0.25 to 0.36 . So, the total entrainment of organic matter at Stations 2 and 3 are estimated to be 1.85 and 7.69 $\mathrm{g} / \mathrm{m}^{2}$, respectively. The total deposition rates at Stations 1 and 4 are 4.1 and $8.92 \mathrm{~g} / \mathrm{m}^{2}$, respectively.

4.3 Transport of FPOM during the flood and the estimation of the total entrainment and deposition fluxes

The entrainment and deposition fluxes of FPOM during the flood period were estimated with the use of the data of water samples. The flowing water from three stations along the river was collected to measure the concentrations of SS and POC. The temporal changes in SS and POC are presented in Figures 3 and 4 , respectively. In addition, the discharge, which is estimated based on water surface level recorded near each station, is also shown.

There are two distinct peaks of discharge. Both of the peaks were accompanied by the peaks of SS and POC. At Station 1, the first peak of discharge was observed at $10 \mathrm{am}$. The peaks of the concentrations of SS and POC were observed at the same time. Before the second peak of discharge appear, SS and POC increase sharply at the beginning of the increase in discharge, and then gradually increase in the next several hours. The peaks of SS and POC were observed four hours after the peak of discharge appeared. It is suggested that the first peak of the SS and POC concentrations were caused by the entrainment in the proximity of Station 1. Similarly, the sudden rise of SS and POC. at the beginning of the second peak of discharge was also due to the entrainment near Station 1. Meanwhile, the second peaks themselves of SS and POC, which reached Station 1 four hours later than the flow peak, was transported from further upstream. This is because the peak of discharge travels downstream faster than the velocity of flow (Kleitz-Seddon's theory) while substances are usually transported with flowing water. The transport processes of fine particles illustrated above needs to be validated by further observations.

Figures 3(b) and 4(b) show the concentrations and the total transport rates of SS and POC at 
Table1 Physical and chemical properties of resuspendable solids available in sediment Before (7 Aug) and after (11 Aug) the occurring of typhoon

\begin{tabular}{|c|c|c|c|c|c|c|c|c|c|c|}
\hline \multirow[b]{2}{*}{ Station } & \multicolumn{3}{|c|}{$\mathrm{SS}\left(\mathrm{mg} / \mathrm{cm}^{2}\right)$} & \multicolumn{3}{|c|}{$\mathrm{POC}\left(\mathrm{mg} / \mathrm{cm}^{2}\right)$} & \multicolumn{2}{|c|}{ C:N:P ratio } & \multicolumn{2}{|c|}{$\begin{array}{l}\text { POC : Organic by } \\
\text { weight ratio }\end{array}$} \\
\hline & 7-Aug & 11-Aug & Dif & 7-Aug & 11-Aug & Dif & 7-Aug & 11-Aug & 7-Aug & 11-Aug \\
\hline $\begin{array}{c}1, \\
\text { (Gravel) }\end{array}$ & 4.39 & 3.86 & .120 & 0.26 & 0.19 & 27.3 & $36: 5: 1$ & $32: 5: 1$ & 0.36 & 0.35 \\
\hline $\begin{array}{c}1, \\
\text { (Mixed bed) }\end{array}$ & 11.16 & 13.65 & 22.3 & 0.41 & 0.52 & 26.8 & 30:5:1 & $32: 5: 1$ & 0.26 & 0.28 \\
\hline 2 & 5.28 & 5.16 & $\begin{array}{l}1.3 .3 \\
\end{array}$ & 0.21 & 0.16 & -25.6 & $23: 5: 1$ & $33: 5: 1$ & 0.27 & 0.26 \\
\hline 3 & 7.06 & 2.88 & 5.59 .2 & 0.29 & 0.09 & -69.1 & $46: 5: 1$ & $29: 5: 1$ & 0.27 & 0.24 \\
\hline 4 & 52.24 & 58.88 & 12.7 & 2.05 & 2.30 & 122 & $43: 4: 1$ & $40: 4: 1$ & 0.28 & 0.28 \\
\hline
\end{tabular}
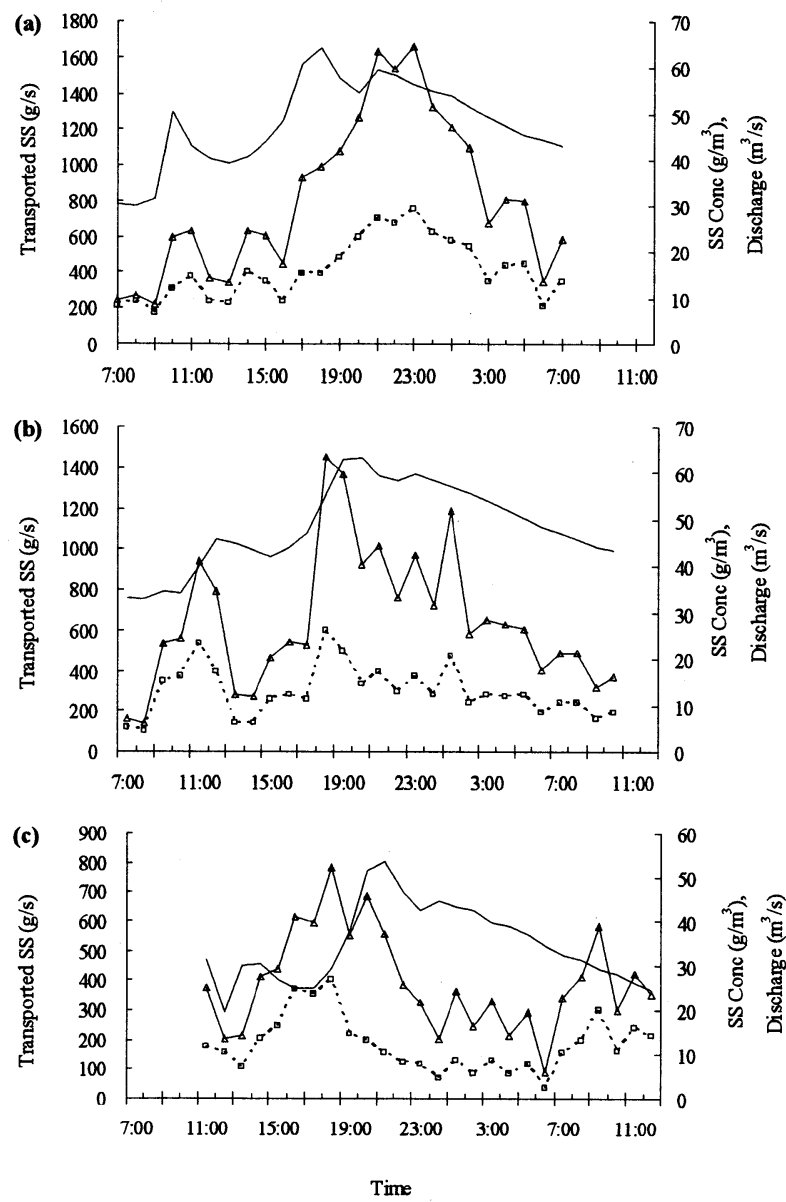

Fig.3 The time variation of the concentration of SS ( $\square)$, the total transport rate of SS $(\triangle)$, and discharge $(-)$ during the flood at (a) Station 1, (b) Station 3, and (c) Station 4.

Station 3. The time variation of discharge and the concentrations of SS and POC show a similar trend. The peaks of both SS and POC concentrations were observed one hour before the peak of flow arrived. It indicates that SS and POC in flowing water collected at Station 3 came from somewhere near the sampling point. In addition, the peak of the total transport of SS at 1:00, 10 Aug., may correspond to the peak of the total SS at Station 1, at 23:00, 9 Aug since Station 3 is located approximately $5.7 \mathrm{~km}$ downstream of Station 1. However, the difference
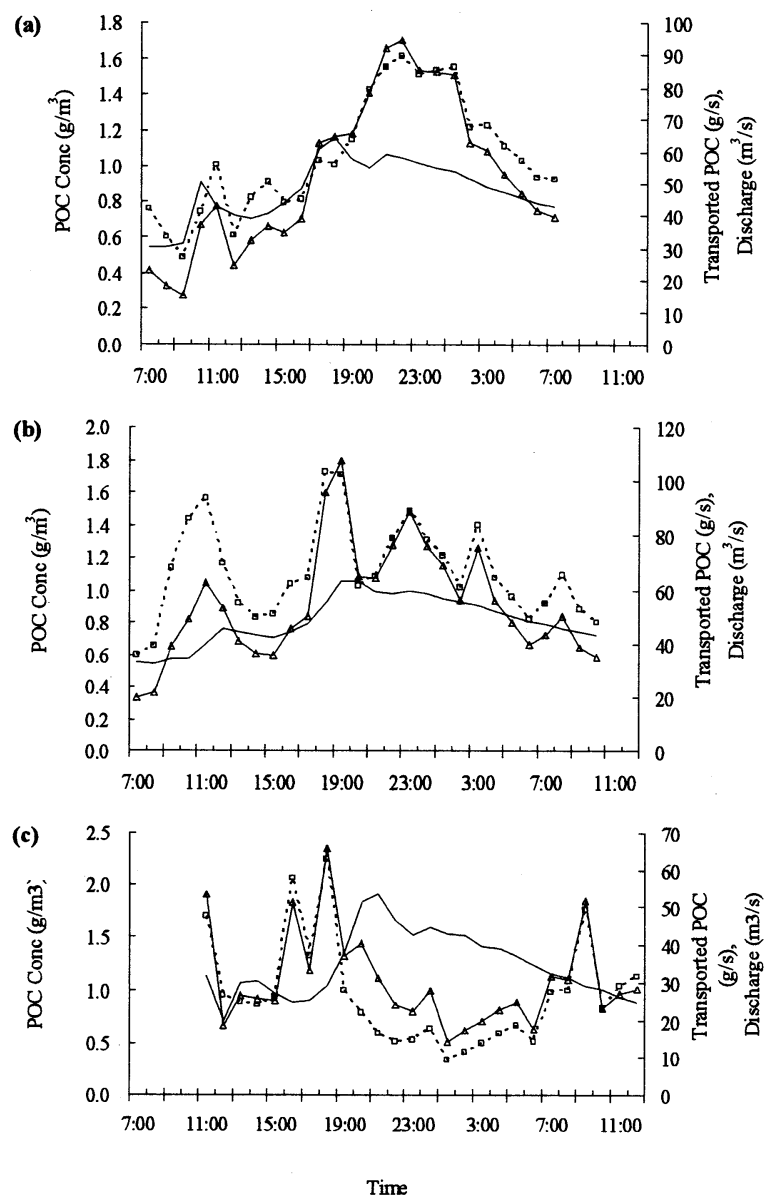

Fig.4 The time variation of the concentration of POC $(\square)$, the total transport rate of POC $(\triangle)$, discharge (-) during the flood at (a) Station 1, (b) Station 3, and (c) Station 4 .

between the transport rates of SS and POC between two stations indicate some deposition occurred in the area between them.

During the sampling period, some water stored by Nakano weir was released to the downstream from 8:45 to 11:00. The abrupt change of discharge and 4(c) because the water sampling started at 11:00. However, the second peaks of SS and POC concentrations were observed very early before the increase in discharge. This may be caused by the tidal effect. Figure 5 shows the relation between the 


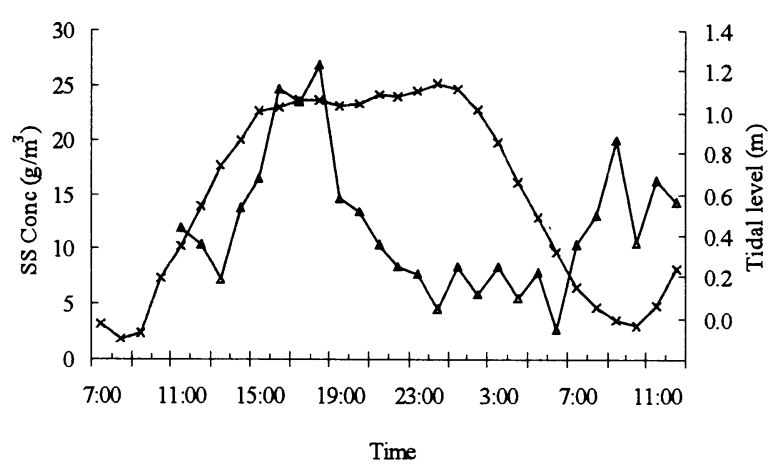

Fig.5 Tidal level at the river mouth during sampling period, 9 Aug. to 10 Aug., 2003 (x) \& SS concentration in flowing water collected at station $4(\triangle)$
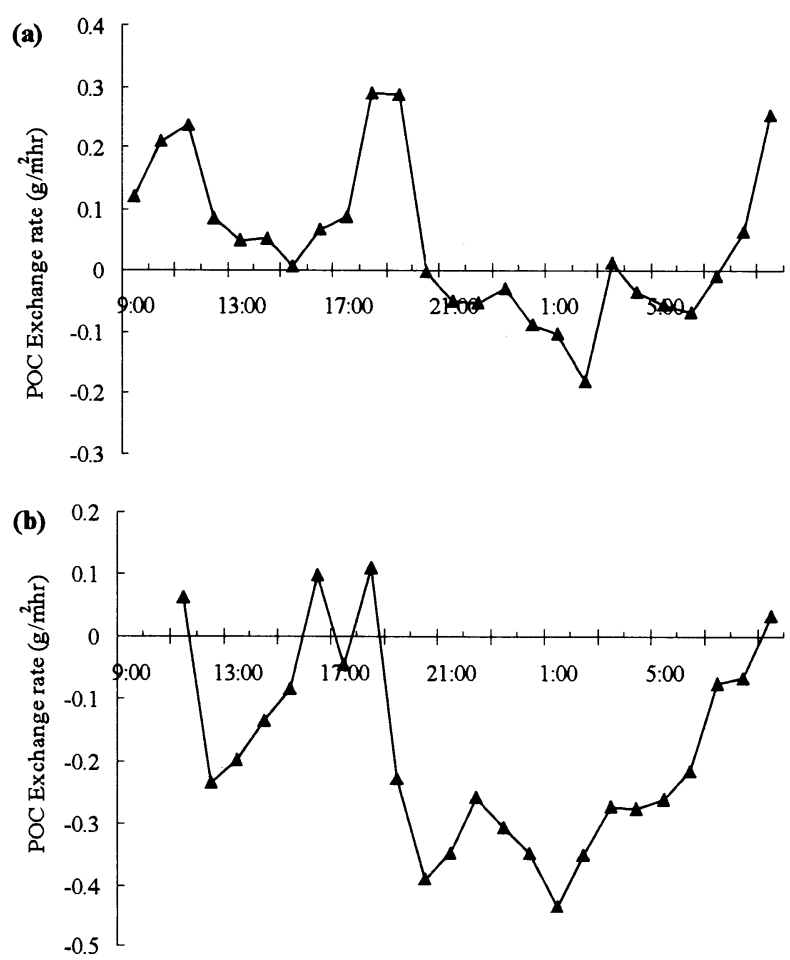

Fig.6 The time variation of the POC exchange rate, (a) between Stations 1 and 2, (b) between Stations 3 and 4.

tidal level at the river mouth and the SS concentration at Station 4. It can be seen that SS increased with increasing tidal level.

Figure 6(a) and (b) show the time variation of the average entrainment and deposition fluxes (exchange rate) of POC in the reach between Stations 1 and 3 and Stations 3 and 4, respectively. The distances of the two reaches are $5.58 \mathrm{~km}$ and $5.35 \mathrm{~km}$, respectively. The total river bed areas of the two reaches are $553,382 \mathrm{~m}^{2}$ and $568,865 \mathrm{~m}^{2}$, respectively. The exchange rate was derived from the balance of the POC transport rate in consideration of the time lag between stations with the flow velocity assumed to be $1 \mathrm{~m} / \mathrm{s}$. In the figures, positive values of the POC exchange rate correspond to the entrainment while negative values
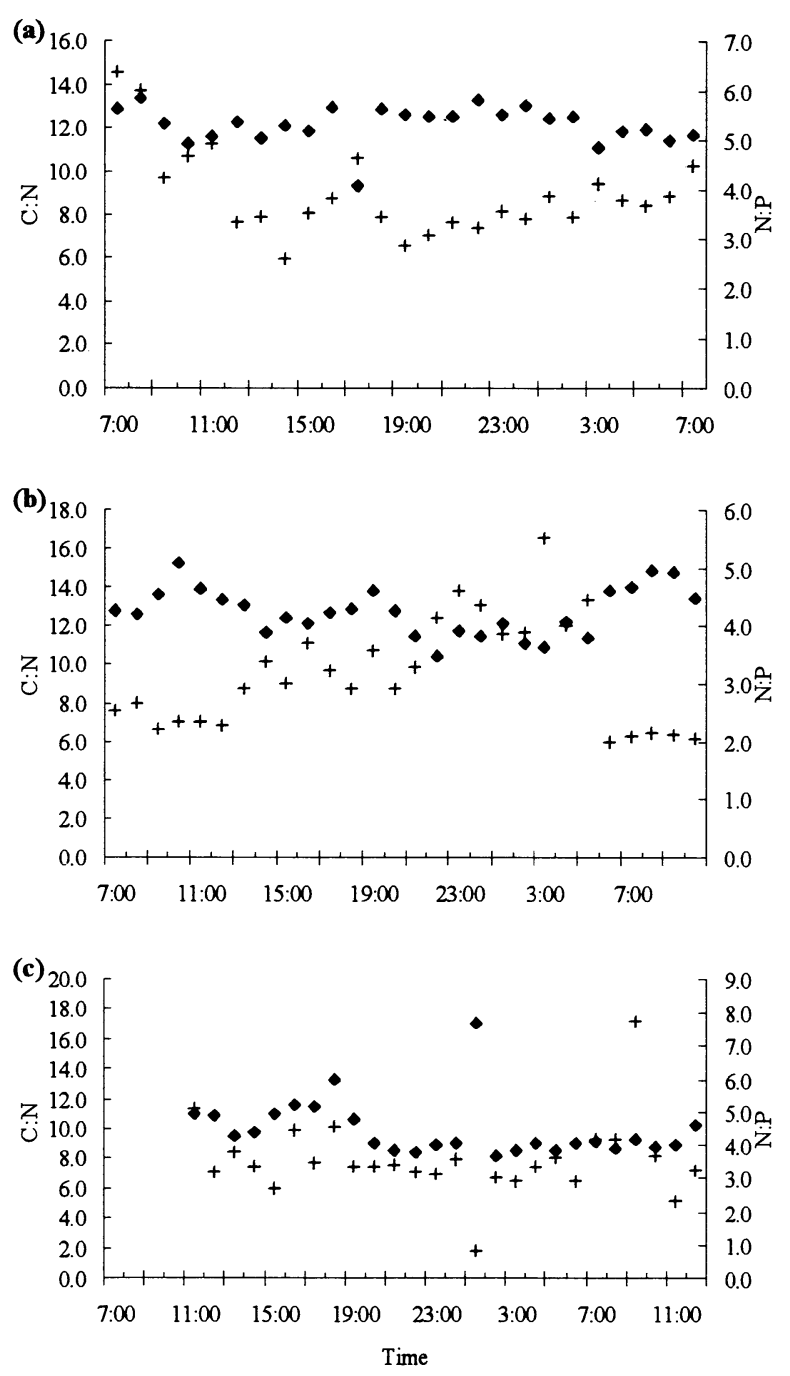

Fig.7 Temporal variation of the component of suspended solids in flowing water during the flood, C: $\mathrm{N}(+), \mathrm{N}: \mathrm{P}$

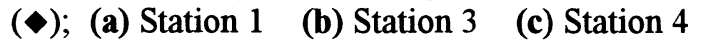

correspond to the deposition. Both figures show that the entrainment occurred at the beginning of the flood while the deposition occurred afterward. Compared between Figures 6(a) and (b), it is found that entrainment is more dominant in the upstream reach, and deposition is more dominant in the downstream reach. This suggests that fine particles entrained in upstream reaches have a tendency to be transported and deposited downstream.

The POC exchange rate integrated from 9:00 on 9 to 8:00 on 10 Aug. averaged in the reach between Stations 1 and 3 was $1.14 \mathrm{~g} / \mathrm{m}^{2}$, implying that the entrainment of POC occurred. According to the estimation from the amount of POC measured between 7 and 11 Aug. described in 4.2, the entrainment of organic matter is $1.85 \mathrm{~g} / \mathrm{m}^{2}$ at Station 2 that is located between Stations 1 and 3. This corresponds to an exchange rate of POC of 0.5 $\mathrm{g} / \mathrm{m}^{2}$. It is natural to assume that some deposition occurred between 10 and 11 Aug. It can be said that 
two estimated values are comparable at least.

\subsection{Origin of FPOM transported during the flood}

The origin of the suspended solids in the flowing water was defined based on the basic components of carbon, nitrogen and phosphorus. The temporal variations of $C: N$ and $N: P$ ratios are shown in Figure 7. The C:N:P ratios of FPOM collected from all stations were not significantly different. It ranges from (34.8-44.4):(4.2-5.3): 1 which is close to Redfield Ratio 41:7.2:1. It indicates that the suspended particles were not carried from terrestrial area outside the river, but originated from inside the river.

\subsection{Size variation of suspended FPOM during the fluctuation of flow}

Figure 8(a) presents the size distribution of SS in samples collected each time at Station 1. The size distribution of suspended particles is almost identical, which ranges from 1.783 to $191.9 \mu \mathrm{m}$ all the time. Figure 8(b) summarizes the representative size at each time in terms of D10, D50 and D90. There was no significant difference in the particle size during the flood. It suggests that the size range of particles which can be resuspended and transported in the flowing water does not depend on the magnitude of discharge fluctuation.

\section{CONCLUSION}

The transport processes of SS and POC were investigated by conducting two field observations: sediment sampling before and after a small flood, and water sampling during the flood in the lower reach of the Nanakita River. Main results are the following:

1) Two typical patterns, in which the peaks of the concentrations of SS and POC appear, are observed. In one pattern, the peaks of SS and POC appear simultaneously with the peak of discharge. In the other pattern, the peaks of SS and POC appear several hours after the peak of discharge. It is suggested that the former pattern appears when the entrainment occurs in the proximity of the sampling points and the latter appears when fine particles are transported from further upstream.

2) It is observed that the entrainment is dominant at the beginning of the flood and the deposition becomes dominant afterwards.
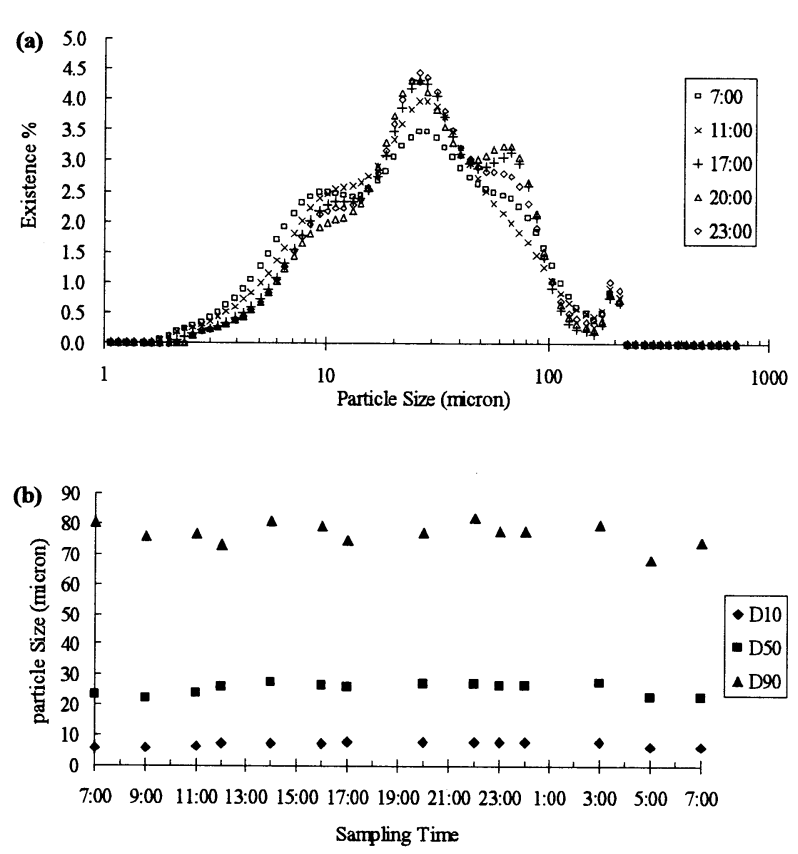

Fig.8 (a) Size distribution of suspended solid in flowing water collected each time during the flood, at Station 1, (b) representative size of suspended particle at each sampling time, at Station 1.

3) The total exchange rates of SS and POC during the flood are found to range from -60 to $50 \mathrm{~g} / \mathrm{m}^{2}$, and -2.5 to $2 \mathrm{~g} / \mathrm{m}^{2}$, respectively, depending on the location.

\section{REFERENCES}

1) Newbold, J.D. et al. "use of ${ }^{14} \mathrm{C}$ Lebel to Study Fine Particulate Organic Matter Dynamics in Flowing Water", Organic Substances and Sediments in Water, Processes and Analysis, Vol.2, 493-501, 2001.

2) Bilby, R.E. and L.E. Gene. "Effect of hydrologic fluctuations of the transport of fine particulate organic carbon in a small stream", Limnol. Oceanogr. 24(1): 6975,1979 .

3) Wetzel, R.G. Limnology: Lake and River Ecosystems. Academic Press, U.S.A., 2001.

4) Hedge, I.J. et al. "Organic matter in Bolivian tributaries of the Amazon River: A comparison to the lower mainstream", Limnol. Oceanogr. 45(7): 1449-1466,2000.

5) Cushing C.E. et al. "Transport dynamics of fine particulate organic matter in two Idaho streams", Limnol. Oceanogr. 38(6): 1101-1115, 1993.

6) Pilailar S. et al. "The influence of physical and biological process on the budget of fine particulate organic matter in the Nanakita river", Proceedings of IWA Conference, (in published)

7) Pilailar S. et al. "The characteristic change of fine particulate organic matter due to a flood in the Nanakita river", Annual J. of Hyd. Eng., JSCE. 47, 1033-1038, 2003.

(Received September 30, 2003) 